\title{
WEAR RED, HELP BEAT HEART DISEASE!
}

\section{By Diane Rochford, President, BSDHT}

Y ou may already be aware that heart disease is one of the biggest killers in the western world. In fact, stroke and cardiovascular disease are responsible for the most deaths each year around the globe, and since the year 2000 , the number of deaths caused by these conditions has risen dramatically.

In 2019, 8.9 million people around the world died from heart disease. ${ }^{1}$ In the $\mathrm{UK}$, one in four individuals currently die of heart disease or circulatory conditions, and this number may even increase in the future if problems such as poor diet and high obesity levels persist. ${ }^{2}$

For dental professionals, heart disease is especially relevant considering that more and more evidence suggests that cardiovascular disorders and dental health are linked.

Information from Harvard Medical School states that individuals who suffer from periodontitis are two to three times more likely to have cardiovascular disorders or strokes in the future. This is because, in simple terms, plaque bacteria cause an inflammatory response in our bodies, so when bacteria enter the blood stream from infected gums, they can cause blockages in the arteries that lead to stroke or cardiac arrest.

So, what can we as dental hygienists and dental therapists do?

The first step is, of course, to explain these links to our patients. Many patients won't be aware of the strong correlation between gum disease and serious conditions, so this is a great opportunity to educate them and explain why the correlation exists. You may find this is especially helpful to explain to patients who routinely present with poor plaque control or who are already suffering from periodontitis - things that they think are only minor concerns can soon become more real to them if you explain how they could impact on their general health in the future.

Another thing to do is to help raise funds to fight against heart disease by joining initiatives such as Wear Red events by the British Heart Foundation. As one of the leading charities fighting against heart

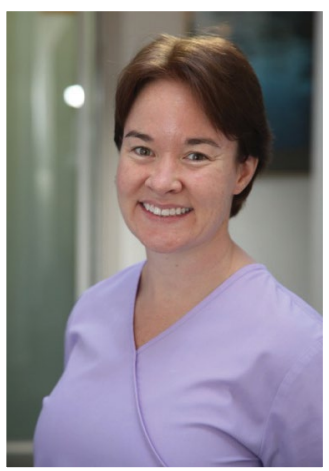

British Heart

Foundation

raises

over $£ 100$ million to aid research into cardiovascular conditions each year.

The Wear Red initiative is simple - you simply encourage staff to wear red to work on a stated day and collect donations from each person. You can even extend this to patients by informing those with appointments on the day in advance and asking them to join in to help a good cause.

There are other options too, and depending on restrictions you may be able to hold a 'Red bake off' or a similar fundraising effort which encourages more donations. Even if certain restrictions are still in place you can raise money by thinking outside the box - perhaps a good option would be to hold a virtual quiz among staff and get people who want to join in to donate? There are plenty of options and whatever funds you do raise will always make a difference.

Heart diseases are serious concerns, especially as they continue to claim the lives of so many people each year. By informing patients and arming them with knowledge, as well as hosting some fundraising events or initiatives, you can do your part in the battle against these serious conditions and help the outlook become brighter.

\section{References}

1. World Health Organization. The top 10 causes of death. 9 December 2020. Available at: https://www.who.int/newsroom/fact-sheets/detail/the-top-10causes-of-death (accessed March 2021).

2. British Heart Foundation. Targeting the world's biggest killers. Available at: https://www.bhf.org.uk/what-we-do/ who-we-are (accessed March 2021).

3. Harvard Health Publishing, Harvard Medical Blog. Gum disease and heart Disease: The common thread. March 2018, updated 15 February 2021. Available at: https://www.health.harvard. edu/heart-health/gum-disease-andheart-disease-the-common-thread (accessed March 2021).

\section{DELIVERY OF SENSORY DENTISTRY TO CHILDREN WITH LEARNING DISABILITIES}

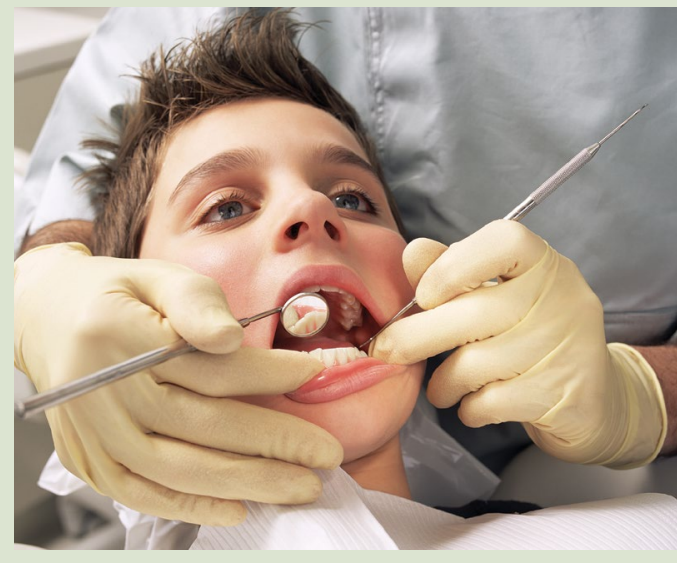

The healthy child e-learning programme (HCP) developed by Health Education England now includes advice on dental issues. The HCP is for all healthcare providers who treat children with learning disabilities and autism in special residential schools and colleges.

The dental advice included is thanks to the input of the British Society of Paediatric Dentistry's (BSPD's) secretary and Consultant in Paediatric Dentistry, Urshla (Oosh) Devalia as well as Wendy Bellis, Honorary Clinical Senior Teaching Fellow at the Eastman Dental Institute.

Some children and young people can have sensory difficulties coping with dental treatment. They do not like the dentist to touch them and the noise and lights of dental practices can make them fearful. The new resource provides carers with advice and techniques for helping children cope with a dental appointment.

The HCP was first developed in 2017 for all health professionals working with pregnant women and children in the first five years of life. The new programme focuses on sensory health services.

Dr Devalia said the programme highlights the adjustments that need to be made to help young people with sensory issues manage in a dental environment. She said: 'Of all the healthcare appointments delivered to children with disabilities, dentistry is probably the most challenging. I am delighted that there is now advice for everyone involved in the care of this cohort of young people which will help them manage a dental appointment'.

https://www.e-lfh.org.uk/programmes/ delivering-sensory-health-services/ 